\title{
Big Data And Rhetoric:
}

\section{Introduction to the Special Issue}

\section{Iulian Vamanu}

University of Iowa

Iowa City, IA

Poroi 16,1 (May 2021)

What does Big Data do to individuals? Can people modify the impact of Big Data on their lives? As the amount of data that people and organizations generate is estimated to reach 100 zettabytes (1 zettabyte $=1$ trillion gigabytes) by 2025 , the possibilities for collecting, storing, and analyzing it are also becoming more and more affordable. As a result, organizations and states are increasingly mining data to extract actionable insights to achieve specific goals, such as profit, social order, and so on.

In this context, Big Data is often constructed as a problem: it raises not only understandable enthusiasm about improved efficiency and decisions, as well as innovation (Finlay, 2014, p. 22), but also gloomy concerns. In fact, such terms as "dictatorship of data," "instrument of the powerful," and "source of repression" are just a few of the ways in which scholars refer to this phenomenon (Mayer-Schönberger \& Cukier, 2013, p. 151). Conjured up here is no less than the specter of a Big Brother society.

But what is Big Data, more precisely? It is a socio-technical phenomenon that involves not only data and analytic practices, but also certain types of agents, organizations; technologies for collecting, storing, analyzing, and using data; as well as beliefs about the kinds of insights it may afford. boyd \& Crawford (2012) capture these three aspects when defining Big Data as "a cultural, technological, and scholarly phenomenon" that builds on the interplay of:

1) Technology: maximizing computation power and algorithmic accuracy to gather, analyze, link, and compare large data sets.

2) Analysis: drawing on large data sets to identify patterns in order to make economic, social, technical, and legal claims. 
3) Mythology: the widespread belief that large data sets offer a higher form of intelligence and knowledge that can generate insights that were previously impossible, with the aura of truth, objectivity, and accuracy. (p. 663)

These aspects of Big Data and their implicit rhetorical implications are the focus of the five studies published in this special issue. They provide fresh perspectives on the points at which Big Data and rhetoric intersect. Specifically, Majdik examines existing definitions of Big Data to articulate "the conceptual similarity between the goals of Big Data analysis and the study of rhetoric." He is interested not only in exploring the ways in which Big Data analysis and rhetorical practices share common goals, but also in how Big Data can support critique, "acting as a lens through which uses and applications of Big Data can be assessed from a rhetorical-humanistic perspective based on Big Data's own functional definitions about what Big Data is and ought to be." Mehlenbacher \& Mehlenbacher focus on Cambridge Analytica, a recent major case of data breach, to discuss the sense in which data can be understood as a form of argument that provides "insights into rhetorical situations, the motives of rhetorical actors, and the broader appeals that shape everything from the kinds of technologies built, to their inclusion in our daily lives, to the infrastructures of cities, the medical practices and policies concerning public health, etc." Lanius looks at contact tracing applications implemented in the United States to argue that they do not do the expected rhetorical work that is needed to motivate action. She concludes that "the promised benefits and myth of a data-driven, technologically empowered utopian society are not here and may never arrive." Adamczyk focuses on the joint congressional hearing "Next Generation Computing and Big Data Analytics" (2013) to argue that "expert witnesses at this hearing draw upon rhetoric traditionally associated with American industrialization. Doing so allows them to articulate Big Data as a resource situated upon a metaphorical, American landscape and thus encourages the public to treat it as a natural resource that must be exploited for the betterment of the nation." In that regard, the author shows that "the use of this rhetoric dissuades critical analysis of the worth of Big Data and investigation of its technical aspects." Finally, building on the psychoanalytical work of Jacques Lacan, Ortega \& Johnson propose the concept of big data drive in regard to biometric big data and explore how Big Data is used as a rhetorical device to represent some of the ways in which people make sense of this phenomenon. 
We hope that this volume will make a solid contribution to the ongoing debates around data rhetoric.

Copyright (C) 2021 Iulian Vamanu

\section{Reference List}

boyd, D., \& Crawford, K. (2012). Critical questions for big data: Provocations for a cultural, technological, and scholarly phenomenon. Information, Communication \& Society, 15(5), $662-679$.

Finlay, S. (2014). Predictive analytics, data mining and big data: Myths, misconceptions and methods. Springer.

Mayer-Schönberger, V., \& Cukier, K. (2013). Big data: A revolution that will transform how we live, work, and think. Houghton Mifflin Harcourt. 